\title{
Progressive cross- and self-sterility associated with aging in fern clones and perhaps other plants
}

\author{
Edward J. Klekowski, Jr
}

Botany Department, University of Massachusetts, Amherst, Massachusetts, 01003, U.S.A.

Plant reproductive cells differentiate from cell lineages derived ultimately from apical meristem initials, cells that are mitotically active throughout the life span of the plant. Because of the chemostat-like properties of these initial-cell populations, the frequency of mutant initials (or apical meristems) will increase as the plant ages. These properties led to three predictions when comparing long-lived species in which the frequency of sexual reproduction varies. The most asexual species should have the highest mean frequency of mutant ramets per chimeric genet, the highest genetic load, and the highest level of genetic load with dominant effects in embryonic and juvenile growth phases. These predictions were confirmed in a study of two fern species.

\section{INTRODUCTION}

It has long been known that Weismann's doctrine (1892) of the separation of soma and germ is invalid in plants. Although plant germ cells ordinarily are produced from undifferentiated cell lineages, these cells are not set aside as in the sex gonads of many mammals (Babcock and Clausen, 1927). Despite this fundamental distinction between higher animals and plants, it is only recently that the genetic and evolutionary ramifications of the lack of a germ line and the importance of somatic mutations have been emphasized (Sutherland and Watkinson, 1986). In general there are two views concerning the importance of somatic mutation in long-lived plants. One view stresses the positive aspects of mutation in the formation of plants that are chimeras where portions of such plants, because of their new genotypes, may have enhanced survivorship in variable biotic or abiotic environments (Whitham and Slobodchikoff, 1981; Buss, 1983; Gill and Halverson, 1984; Silander, 1985). The other view, while noting that occasional adaptive somatic mutations may occur, emphasizes mutational load and the negative as pects of genotype deterioration as the most important consequences of somatic mutation in long-lived plants (Klekowski, in press; Klekowski, 1988). In this article evidence for extensive mutational load in long-lived plants will be presented.

\section{PLANTS AS CHEMOSTATS}

Considered from the perspective of somatic mutation, plants may be viewed as microbial chemostats with tissue organization (Klekowski, in press; Klekowski, 1988). A chemostat is a device whereby a microbial population may be maintained in a continuous growth phase for an indefinite period of time. This is accomplished by a continuous flow of fresh nutrient medium into the culture vessel and the simultaneous removal of old medium and cells from the culture vessel. In many respects the various meristems of a vascular plant are analogous to a chemostat. For example in the apical meristems, the population of apical initials is in continuous growth phase (at least during the growing season), the excess cells formed are "washed out" to the soma, and finally there is a continuous flow of nutrient medium (water, minerals, photosynthate) into the meristem. Novick and Szilard (1950, 1951), studied the dynamics of spontaneous mutation in microbial chemostats. The general principles that they developed can be applied to multicellular plants to give an appreciation of the impact of continued somatic mutation during plant growth.

The growth of a newly established cell culture is characterized by a phase of logarithmic growth. The derivative of this part of the growth curve is $\mathrm{d} n / \mathrm{d} t=\alpha n$, where $t$ is time, $n$ is cell number per unit volume and $\alpha$ is the growth rate. The 
reciprocal value, $\gamma=1 / \alpha$, is designated as the generation time. In a chemostat the cell population is maintained in growth phase indefinitely. The consequences of spontaneous mutations in such a system are interesting. If the mutations are neutral (i.e., no selection for or against the mutant with respect to the wild-type cell), then the mutations will increase linearly with time. If we disregard back mutation then, in terms of cell numbers per unit volume, $\mathrm{d} n^{*} / \mathrm{d} t=(\lambda / \gamma) n$, where $n^{*}$ is the mutant, $n$ the wild type, and $\lambda$ the number of mutations produced per generation per cell. Separating variables and integrating both sides then $n^{*} / n=(\lambda / \gamma) t+$ constant; thus the relative abundance of the mutants increases linearly with time. In plants, therefore, the frequency of mutant initials (or ramets or branches) should increase as a genet ages.

The chemostat analogy holds primarily for the case when mutant cells and wild type cells have equal fitness within the organism. In plants the chemostat operates primarily during periods of vegetative or clonal growth. During such periods, since a higher plant is at least diploid, recessive mutations can accumulate at all loci. In addition both dominant and recessive mutations could accumulate at loci whose expression is important only during embryonic and juvenile growth phases as well as at loci governing sexual reproduction (meiosis, spore formation, gametophyte and gamete development). Thus one would predict that if two long-lived plant species are compared with regard to genetic load characteristics, the species in which vegetative reproduction predominates would have the following load characteristics.

(1) The higher mean frequency of mutant ramets per chimeric genet (and a larger clone to clone variation for this trait as well).

(2) The higher genetic load.

(3) A higher frequency of mutants with dominant effects for embryonic and juvenile growth phases and for aspects of sexual reproduction.
In this communication the genetic load characteristics for two fern species are compared. Onoclea sensibilis (sensitive fern) reproduces vegetatively by creeping rhizomes. Successful sexual reproduction is also common in this species. Populations consist of numerous genets which are continuously invaded by new genets of sexual origin. In contrast, Matteuccia struthiopteris (ostrich fern) almost solely reproduces vegetatively (via stolons); successful sexual reproduction is very rare. Populations typically consist of one or a few very old and large genets (see Klekowski, 1984 for further discussion of the ecology and organography of these two species). Both species have similar chromosome numbers (O. sensibilis $n=37, M$. struthiopteris $n=40$ ), are diploid, and often occupy the same habitats. Both species have been the subject of a number of genetic load studies (Ganders, 1972; Saus and Lloyd, 1976; Klekowski, 1984); thus considerable data are available for comparative analysis (see these publications for procedures and culture methods).

All populations are located in the Connecticut River Valley in Massachusetts (table 1). Mendelian mutants are distinct gametophyte phenotypes that segregated in the spore samples in $1: 1$ ratios, presumptive chromosome aberrations are recognized by a high frequency of inviable spores and a variety of aberrant gameotype morphologies in the spore sample, the spore morphology mutant is a clone that has fixed a mutation affecting sporogenesis. One clone in the Hatfield Oxbow was a chimera for both a Mendelian mutant and a presumptive chromosome aberration.

\section{FREQUENCY OF MUTANT RAMETS}

In ferns the mutation rate per ramet-doubling generation time for gametophyte mutations can be easily measured (Klekowski, 1984). Individual ramets within a genet are sampled for spores and

Table 1 Somatic mutations in clones of Matteuccia struthiopteris

\begin{tabular}{|c|c|c|c|c|c|c|}
\hline \multirow[b]{2}{*}{ Populations } & \multirow{2}{*}{$\begin{array}{l}\text { Clones } \\
\text { studied }\end{array}$} & \multirow{2}{*}{$\begin{array}{l}\text { Apices } \\
\text { (ramets) }\end{array}$} & \multirow{2}{*}{$\begin{array}{l}\text { Mutant-free } \\
\text { clones }\end{array}$} & \multicolumn{3}{|l|}{ Chimeras } \\
\hline & & & & Mendelian & Chromosome & Spore morphology \\
\hline Hatfield Oxbow & 13 & 213 & 7 & 2 & 4 & 1 \\
\hline Ned's Ditch & 4 & 38 & 3 & 1 & & \\
\hline Whately Oxbow & 3 & 40 & 2 & 1 & & \\
\hline Roaring Brook, Mt. Toby & 1 & 40 & & 1 & & \\
\hline Cave Hill, Leverett & 2 & 33 & & 2 & & \\
\hline Deerfield River & 4 & 60 & 3 & 1 & & \\
\hline Mill River, Hatfield & 4 & 100 & 1 & 2 & 2 & \\
\hline Total & 31 & 524 & 16 & 10 & 6 & 1 \\
\hline
\end{tabular}


the frequency of ramet spore samples in which gametophyte mutants segregate is determined. The mutation rate is calculated from the frequency of clones lacking mutant ramets (the zero term of a Poisson distribution whose mean is the product of the mutation rate times the number of ramet-doubling generations). In table 1 the data for 31 clones of $M$. struthiopteris are shown. Some of these clones were chimeras either for mutant gametophyte phenotypes which segrated in $1: 1$ ratios, or for presumptive chromosome aberrations which resulted in high levels of aborted spores and variously abnormal gametophytes, or in one case for a mutant which disrupted spore maturation (almost all spores formed were incapable of germination). The mutation rates were calculated as 0.0269 for gametophyte mutants showing $1: 1$ segregations, 0.0148 for chromosome aberrations, and the total mutation rate for all classes of mutation was 0.0388 mutations per ramet-doubling generation per apical initial. These values are similar to the previously measured mutation rates in $M$. struthiopteris for gametophyte mutations $(0.0177)$ and for $O$. sensibilis for all classes of mutation $(0.0341)$ (Klekowski, 1984). Thus the two fern species have nearly identical mutation rates.

In table 2 the frequencies of mutant ramets per clone in each species are given. The mean frequency of mutant ramets in clones that are a chimera in $M$. struthiopteris is more than twice the value of $O$. sensibilis, $(t(29 \mathrm{df})=2.7915, P<0.01)$. The standard deviation for the frequency of mutant ramets per genetically mosaic clone is three fold

Table 2 Frequency of mutant apices (ramets) per mosaic clone (genet) in the fern species, Onoclea sensibilis and Matteuccia struthiopteris

\begin{tabular}{lll} 
& Onoclea & Matteuccia \\
\hline 0.1 & 0.25 \\
0.167 & 1.0 \\
0.375 & 0.4 \\
0.30 & 0.9 \\
0.077 & 1.0 \\
0.391 & 0.1 \\
0.167 & 0.071 \\
0.167 & 0.15 \\
0.177 & 0.30 \\
0.231 & 0.923 \\
0.375 & 0.273 \\
& 0.091 & 0.258 \\
0.05 & 0.133 \\
& 0.1 & 0.415 \\
0.2 & 1.0 \\
Mean & 0.4 & - \\
Standard deviation & 0.2105 & 0.4782 \\
& 0.1212 & 0.3696 \\
\hline
\end{tabular}

larger in $M$. struthiopteris, $(F(13,14 \mathrm{df})=9.30, P<$ $0 \cdot 01$, equality of variance comparison). One would predict from the chemostat analogy that the longer a genet grows the greater should be the variation in the proportion of mutant ramets since mutations can occur over a longer time period.

\section{GENETIC LOAD}

In ferns, genetic load for recessive sporophytic lethals can be easily measured (see Klekowski, 1979 for details and Hedrick, 1987 for a review). Summarizing the published results (Ganders, 1972; Saus and Lloyd, 1976), O. sensibilis has an average of 0.294 lethal equivalents per haploid spore $(25.4$ per cent of the spores developed hermaphroditic gametophytes that were incapable of forming viable homozygous sporophytes). In $M$. struthiopteris 164 spore genotypes were screened for sporophytic genetic load. These spores represented a random sample of haploid genotypes generated by the clones in table 1 . Of the spores that gave rise to hermaphroditic gametophytes, only 5.5 per cent of these gametophytes developed viable homozygous sporophytes upon selfing. Thus 94.5 per cent of the spores of $M$. struthiopteris carried sporophytic lethals in contrast to $25 \cdot 4$ per cent in $O$. sensibilis. If one assumes that 100 per cent of the gametophytes could form viable sporophytes if outbreeding occurred (a questionable assumption as will be shown), then $M$. struthiopteris has on the average 2.9 lethal equivalents per spore or $5 \cdot 8$ lethal equivalents per zygote. This is the highest genetic load so far documented in the ferns (Hedrick, 1987).

\section{DOMINANT LOAD IN REPRODUCTIVE PHASES}

In addition to recessive sporophyte lethals an additional load component was documented in $M$. struthiopteris: dominant sporophytic lethals or dominant load. A total of 112 non-sib, non-genet pairs of hermaphroditic gametophytes was cultured as controls for the above genetic load study. After prolonged culture, only 77 (68.8 per cent) of these pairs formed viable sporophytes. The remaining 35 pairs were subcultured and each gametophyte was fertilized with a variety of sperm genotypes from different genets and ramets within genets. Only an additional sixteen pairs formed sporophytes; nineteen pairs ( 17 per cent) failed to form viable embryos regardless of the sperm genotypes used in the cross fertilizations. In $O$. 
sensibilis, Saus and Lloyd (1976) also documented such gametophyte genotypes. These authors reported that 2 per cent of the gametophytes in their study exhibited dominant load (i.e., failed to form viable sporophytes regardless of sperm genotype). Thus $M$. struthiopteris has a much higher genetic load than $O$. sensibilis, both for recessive and dominant components of genetic load. Such a dominant load may represent the somatic accumulation of mutations with dominant effects in various aspects of the embryonic and sporeling stages of sporophyte development.

It is worth noting that such a dominant load is not restricted to these two fern species. Numerous studies of genetic load in long-lived angiosperms and gymnosperms (table 3 ) have documented similar phenomena in the offspring resulting from outbreeding. This dominant load has often led to spurious genetic load estimates in these plants (Klekowski, 1988). In table $3, S_{1}$ is the viability of offspring resulting from outcrossing. The ratio $S_{0} / S_{1}$, where $S_{0}$ is the viability of offspring resulting from inbreeding, is used to estimate the genetic load in lethal equivalents (Sorensen, 1969; Morton, Crow and Muller, 1956). In long-lived plants the $S_{1}$ values are often low and consequently many genetic load estimates in these organisms are spurious. For example Picea omorika is often cited as a conifer without genetic load because the $S_{1}$ and $S_{0}$ values are similar and the large $S_{0} / S_{1}$ ratio gives a low number of lethal equivalents, yet the general viability of offspring produced by this species is very low, c. 0.166 considering only early embryonic viability. Such dominant load is gen- erally associated with a long life span in plants and is strong evidence for a chemostat effect for gene-loci which are important in the process of sexual reproduction.

In $M$. struthiopteris one instance of dominant load expressed in the reproductive phase was studied in some depth. One clone was found in which all of the spores formed by the sporophylls were unable to germinate. This clone was subdivided into a series of subclones covering an area of $360 \times 10 \mathrm{~m}$ along the edge of an oxbow lake next to the Connecticut River (Hatfield Oxbow, Great Pond) and consists of over 1000 ramets. Cytological investigation showed that meiosis was normal but that post-meiotic maturation of the spores was defective. The meiotic cell divisions following telophase II were abnormal so that variously aborted tetrads, spore diads as well as spores that contained all four telophase II nuclei were formed; almost all of these spores were unable to germinate. This clone appears to have fixed a dominant mutation that disturbs normal sporogenesis.

Muller (1949) noted that the mere maintenance of a structure or function requires the persistent operation of natural selection. Since negative genetic changes that disrupt a structure are much more common than those that increase or intensify an organ or character, Muller suggested that the disappearance of eyes and pigmentation in cave animals is due to the accumulation of random tions that are relatively neutral in cave environments. The genetic decay of characters pertaining to sexual reproduction was documented in a

Table 3 Survivorship of progeny resulting from outcrossing $\left(S_{1}\right)$ and phenotypic criteria used to determine viability

\begin{tabular}{|c|c|c|c|}
\hline Species & $S_{1}$ & Phenotype & Reference \\
\hline Phlox drummondii (annual) & 0.876 & seed abortion & Levin, 1984 \\
\hline Ulmus americana & $\begin{array}{l}0.55 \\
0.68 \\
(0.55)(0.68)=0.374\end{array}$ & $\begin{array}{l}\text { seed set } \\
\text { seed germination } \\
\text { general viability }\end{array}$ & Lester, 1971 \\
\hline Acer saccharum & 0.349 & seed set & Gabriel, 1967 \\
\hline Larix laricina & $\begin{array}{l}0.389 \\
0 \cdot 750 \\
(0 \cdot 389)(0 \cdot 750)=0.291\end{array}$ & $\begin{array}{l}\text { sound seed } \\
\text { seedling survival } \\
\text { general viability }\end{array}$ & Park and Fowler, 1982 \\
\hline Picea glauca & $0.322,0.507$ & sound seed & Coles and Fowler, 1976 \\
\hline P. mariana & $\begin{array}{l}0.63,0.70 \\
0.71,0.80 \\
(0.70)(0.80)=0.56\end{array}$ & $\begin{array}{l}\text { seed germination } \\
\text { seedling survival } \\
\text { general viability }\end{array}$ & Park and Fowler, 1984 \\
\hline P. omorika & $\begin{array}{l}0.334 \\
0.497 \\
(0.334)(0.497)=0.166\end{array}$ & $\begin{array}{l}\text { full seeds } \\
\text { seed germination } \\
\text { general viability }\end{array}$ & Langner, 1959 \\
\hline Pinus resinosa & $0 \cdot 72$ & full seed & Fowler, 1965 \\
\hline Pseudotsuga menziesii & 0.685 & sound seeds & Sorensen, 1969 \\
\hline
\end{tabular}


parthenogenetic laboratory strain of Drosophila mercatorium (Carson, Chang and Lyttle, 1982). In Tribolium castraneum, Sokal (1970) presented evidence for the accumulation of late-acting deleterious mutations in strains in which young adult insects were killed shortly after the onset of reproduction for 40 generations.

Although the vascular plant Bauplan makes plants especially sensitive to such mutational decay, botanists have generally not been cognisant of Muller's idea. Consequently, studies that have focused on this phenomenon are rare. The data on dominant genetic load (table 3 ) certainly support the hypothesis that the accumulation of mutations in portions of the genome buffered from selection is important in many different plant species. In Populus the sterility of some clones has been related to their relative ages. Smith (1943) reported that the average number of univalents at meiosis in similar Populus hybrids was higher in older clones (table 10 in Smith, 1943). In Pelargonium a haploid cultivar (Kleine Liebling) has been in cultivation for over 40 years and has been subjected to hundreds of cycles of vegetative propagation. Daker (1967) reported that a diploid colchicine derivative of this variety had a highly aberrant meiosis. Daker hypothesized that this clone had accidentally fixed a deleterious mutation affecting meiosis during the extensive period of vegetative reproduction.

\section{CHIMERISM}

The chemostat-analogy also leads to the prediction that genets are not infrequently chimeras for components of mutational load. Such chimerism has already been documented for gametophytic mutations (tables 1 and 2). Clones that fixed gametophyte mutations were used to study chimerism for recessive sporophytic lethals. The logic was to use clones that fixed a distinctive gametophyte mutant and use this mutant to mark the ramets of a single genet. The different ramets were then compared for allelism of recessive sporophytic lethals. Allelism was measured by establishing random pairs of gametophytes from the same ramet (sib pairs) and random pairs of gametophytes from different ramets of the same genet (cross pairs). If recessive sporophytic lethals accumulated in the ramets after the marker gametophyte mutation occurred, then the frequency of sporophytes in the cross pairs should exceed the number in the sib pairs. In table 4 the experimental results for five M. struthiopteris clones are shown. One out of five
Table 4 Post-zygotic recessive sporophytic lethals in Matteuccia clones

\begin{tabular}{llll}
\hline & & $\begin{array}{l}\text { Pair } \\
\text { cultures } \\
\text { established }\end{array}$ & $\begin{array}{l}\text { Pair } \\
\text { cultures } \\
\text { with } \\
\text { sporophytes }\end{array}$ \\
\hline Sib pairs & RB35 & 25 & 7 \\
Sib pairs & RB12 & 25 & 5 \\
Cross pairs & RB35 $\times$ RB12 & 25 & 16 \\
Sib pairs & CH19 & 25 & 8 \\
Sib pairs & CH8 & 25 & 7 \\
Cross pairs & CH19 $\times$ CH8 & 25 & 6 \\
Sib pairs & H60 & 35 & 9 \\
Sib pairs & H69 & 35 & 12 \\
Cross pairs & H60 $\times$ H69 & 36 & 7 \\
Sib pairs & DB13 & 35 & 6 \\
Sib pairs & DB3 & 35 & 6 \\
Cross pairs & DB13 $\times$ DB3 & 35 & 7 \\
Sib pairs & P28 & 35 & 9 \\
Sib pairs & P13 & 35 & 10 \\
Cross pairs & P28 $\times$ P13 & 35 & 12 \\
& & & \\
\hline
\end{tabular}

Clone origins are: $\mathrm{RB}$ is from Roaring Brook, Mt Toby; DB and $\mathrm{CH}$ are from Cave Hill, Leverett; $\mathrm{H}$ is from the Hatfield Oxbow, and P is from the Deerfield River.

The apices RB35 and RB12 have accumulated recessive sporophytic lethals since their origin from a common apex. $\left(\underline{P}<0.01,3 \times 2 \chi^{2}, \mathrm{df}=2\right)$

of the clones was heterozygous for post-zygotic recessive sporophytic lethals that occurred after the marker gametophyte mutation (clone $\mathrm{RB}, 3 \times$ $\left.2 \chi^{2}(2 \mathrm{df})=11.745, P<0.01\right)$.

Although specific studies of chimerism within long-lived plants are rare, Eiche's (1955) study of populations of Pinus sylvestris is suggestive that such chimerism is extensive. This species forms male and female cones on the same branches and can self-pollinate. Seeds from 2031 open pollinated trees were progeny tested for albino seedlings. Based upon a sample of $1.7 \times 10^{6}$ seedlings, an albino frequency of approximately $1.5 \times 10^{-3}$ was determined. A total of 705 (c. 35 per cent) trees segregated albino seedlings in their progeny. Segregation frequencies for "mutant" trees varied from 0.25 albinos (one tree) to much lower frequencies of 0.085 to 0.001 with a modal value of 0.004 albinos per mutant tree seed sample. Two explanations are prompted by these findings; either 35 per cent of these trees were heterozygotes for recessive albino alleles or approximately 35 per cent of these trees were chimeras, i.e., the crowns had branches heterozygous for chlorophyll-deficient alleles and that these alleles arose as post-zygotic mutations. The former explanation attributes the low and variable albino frequencies to varying degrees of 
crossing with trees not carrying allelic mutations, whereas the latter explanation considers the variable albino frequencies to be due primarily to the chemostat effect. Thus as an individual tree aged, the frequency of mutant apices increased following the pattern of a chemostat. The variable albino frequencies therefore reflect primarily the proportion of mutant branches in a tree crown (see table 2 for similar variation in mutant ramet frequencies in the two ferns). If this latter explanation is correct, then approximately 35 per cent of the $P$. sylvestris trees in Scandanavia are to some extent chimeras for albinism.

In conclusion, genetic load comparisons between $O$. sensibilis and $M$. struthiopteris support the chemostat analogy. Recently there has been considerable interest in the importance of genetic load and inbreeding depression in the evolution of sexual reproductive strategies (Lande and Schemske, 1985; Schemske and Lande, 1985; Charlesworth and Charlesworth, 1979). The plant Bauplan and lack of a germline coupled with the long life spans found in many species lead to the suggestion that compensating for mutational load (both post-zygotic mutations and those inherited from previous generations) may be a very important adaptive concern in these organisms. Such compensations may take the form of increased genomic buffering against mutation, developmental homeostasis and canalization, reproductive cycles that enhance the loss of defective gametophytes, gametes and offspring, outcrossing to reduce the immediate phenotypic consequences of mutant alleles and recombination to generate genotypes with fewer mutant alleles than the parents (Klekowski, 1988).

Acknowledgements I thank Leonid Fukshansky (Universität Freiburg, BRD) for stimulating discussions, Libby Klekowski for technical assistance, Jacob Schneller (Institut für Systematische Botanik, Zürich, Switzerland) for help with aspects of the field work, and John Buonaccorsi of the University of Massachusetts Statistical Consulting Center for help with the statistics. This work was supported by grants from the Alexander von Humboldt Stiftung (Bonn) and the U.S. National Science Foundation (DCB 8519018).

\section{REFERENCES}

BABCOCK, E. B. AND CLAUSEN, R. E. 1927. Genetics in Relation to Agriculture. McGraw Hill, New York.

BUSS, L. W. 1983. Evolution, development, and the units of selection. Proc. Natl. Acad. Sci. USA, 80, 1387-1391.

CARSON, H. L., CHANG, L. S. AND LyTtLE, T. W. 1982. Decay of female sexual behavior under parthenogenesis. Science, $218,69-70$.
CHARLESWORTH, B. AND CHARLESWORTH, D. 1979. The evolutionary genetics of sexual systems in flowering plants. Proc. Roy. Soc. London B, 205, 513-530.

COLES, J. F. AND FOWLER, D. P. 1976. Inbreeding in neighboring trees in two white spruce populations. Silvae Genetica, 25, 29-34.

DAKER, M. G. 1967. Cytological studies on a haploid cultivar of Pelargonium, and its colchicine-induced diploids. Chromosoma, 21, 250-271.

EICHE, v. 1955. Spontaneous chlorophyll mutations in scots pine (Pinus silvestris L). Meddn. St. Skogsforsk Inst., 45 (13), 1-69.

FOWLER, D. P. 1965. Effects of inbreeding in red pine, Pinus resinosa Ait IV. Comparison with other northeastern Pinus species. Silvae Genetica, 14, 76-81.

GABRIEL, W. J. 1967. Reproductive behavior in sugar maple: Self-compatibility, cross-compatibility, agamospermy, and agamocarpy. Silvae Genetica, 16, 165-168.

GANDERS, F. R. 1972. Heterozygosity for recessive lethals in homosporous fern populations: Thelypteris palustris and Onoclea sensibilis. Bot. J. Linn. Soc., 65, 211-221.

GILL, D. E. AND HALVERSON, T. G. 1984. Fitness variation among branches within trees. In Shorrocks, B. (ed.) Evolutionary Ecology, Blackwell Scientific Publications, Oxford, pp. 105-116.

HEDRICK, P. W. 1987. Genetic load and the mating system in homosphorous ferns. Evolution, 41, 1282-1289.

KLEKOWSKI, E. J., JR. 1979. The genetics and reproductive biology of ferns. In Dyer, A. F. (ed.) The Experimental Biology of Ferns, Academic Press, New York, pp. 133-170.

KLEKOWSKI, E. J., JR. 1984. Mutational load in clonal plants: A study of two fern species. Evolution, 38, 417-426.

KLEKowSKI, E. J., JR. 1988. Mutation, Developmental Selection, and Plant Evolution. Columbia University Press, New York.

KLEKOWSKI, E. J., JR. Mechanisms that maintain the genetic integrity of plants. In Greuter, W. and Zimmer, B. (eds.) Proceedings of the XIV International Botanical Congress, Koeltz, Königstein/Taunus (In press).

LANDE, R. AND SCHEMSKE, D. W. 1985. The evolution of self-fertilization and inbreeding depression in plants. I. Genetic models. Evolution, 39, 24-40.

LANGNER, w. 1959. Selbsfertilität and Inzucht bei Picea omorika (Pancic) Purkyne. Silvae Genetica, 8, 84-93.

LESTER, D. T. 1981. Self-compatibility and inbreeding depression in American elm. For. Sci., 17, 321-322.

LEVIN, D. A. 1984. Inbreeding depression and proximity-dependent crossing success in Phlox drummondii. Evolution, 38 , 116-127.

MORTON, N. E., CROW, J. F. AND MUller, H. J. 1956. An estimate of the mutational damage in man from data on consanguineous marriages. Proc. Natl. Acad. Sci. USA, 42, $855-863$

MULLER, H. J. 1949. The Darwinian and modern conceptions of natural selection. Proc. Amer. Philos. Soc., 93, 459-470.

NOVICK, A. AND SZILARD, L. 1950. Experiments with the chemostat on spontaneous mutations of bacteria. Proc. Natl. Acad. Sci. USA, 36, 708-719.

NOVICK, A. AND SZILARD, L. 1951. Genetic mechanisms in bacteria and bacterial viruses. I. Experiments on spontaneous and chemically induced mutations of bacteria growing in the chemostat. Cold Spring Harbor Symp. on Quantitative Biology, 16, 337-343.

PARK, Y.S. AND FOWLER, D. P. 1982. Effects of inbreeding and genetic variances in a natural population of tamarack (Larix laricina (Du Roi) K. Koch) in eastern Canada. Silvae Genetica, 31, 21-26. 
PARK, Y. S. AND FOWLER, D. P. 1984. Inbreeding in black spruce (Picea mariana (Mill.) B.S.P.): self-fertility, genetic load, and performance. Can. J. For. Res., 14, 17-21.

SAUS, G. L. AND LLOYD, R. M. 1976. Experimental studies on mating systems and genetic load in Onoclea sensibilis $\mathrm{L}$. (Aspleniaceae: Athyrioideae). Bot. J. Linn. Soc., 72, 101113.

SCHEMSKE, D. W. AND LANDE, R. 1985. The evolution of self-fertilization and inbreeding depression in plants. II. Empirical observations. Evolution, 39, 41-52.

SILANDER, J. A., JR. 1985. Microevolution in clonal plants. In Jackson, J. B. C., Buss, L. W. and Cook, R. E. (eds) Population Biology and Evolution of Clonal Organisms. Yale University Press, New Haven, pp. 107-152.
SMITH, E. C. 1943. A study of cytology and speciation in the genus Populus L. J. Arn. Arbor., 24, 275-305.

SOKAL, R. R. 1970. Senescence and genetic load: Evidence from Tribolium. Science, 1733-1734.

SORENSEN, F. 1969. Embryonic genetic load in coastal Douglas-Fir, Pseudotsuga Menziesii var. Menziesii. Amer. Natur., 103, 389-398.

SUTHERLAND, W. J. AND WATKINSON, A. R. 1986. Do plants evolve differently? Nature, 320, 305

WeISMANN, A. 1892. Das Keimplasma. Eine Theorie der Vererbung. Fischer, Jena, Germany.

WHITHAM, T. G. AND SLOBODCHIKOFF, C. N. 1981. Evolution by individuals, plant-hervibore interactions, and mosaics of genetic variability: The adaptive significance of somatic mutations in plants. Oecologia (Berl), 49, 287-292. 